\title{
Reduction of Voltage Ripple in DC Link of Wind Energy Conservation System Using Modified DC-DC Boost Converter
}

\author{
L. HUBERT TONY RAJ ${ }^{a, 1}$, R. SIVAKUMAR ${ }^{b}$, R.AKASH $^{b}$ and \\ M. ANANDHA CHAKRAVARTHI ${ }^{\mathrm{b}}$ \\ ${ }^{a}$ Assistant Professor, Department of EEE, SRM TRP Engineering College, TN, India \\ ${ }^{\mathrm{b}} U G$ Student, Department of EEE, SRM TRP Engineering College, TN, India
}

\begin{abstract}
Renewable energy provisions must be extracted in a more resourceful way, with a power converter added to the mix. If the supply-demand curve rises with the seasons, it becomes clear that renewable energy sources are used to provide clean energy. This clean energy cannot be used on load directly due to fluctuating conditions, to solve this problem a modified DC to DC converter with a ripple-free output is introduced. The Vertical Axis Wind Turbine (VAWT) and Solar PV were combined to achieve a constant DC output in a hybrid renewable energy conversion system. For renewable energy applications, a redesigned converter with ripple-free output is used. The simulation is made under MATLAB/SIMULINK and experimental parameters were measured using a nominal prototype.
\end{abstract}

Keywords. VAWT, Solar PV, Hybrid system and Ripple

\section{Introduction}

Renewable electricity sources including photovoltaic (PV) and wind power account for the majority of overall renewable energy production in India. Since both origins are sporadic in nature, for a stable operation, successful solutions are needed [1]. PV and wind have the intrinsic advantage of being complementary in design. As a result, combining PV and wind energy sources will help to mitigate long-term intermittency to some degree.

A hybrid energy system combines multiple energy sources (two or more) with effective energy conversion technologies. linked to provide electricity to the local load/grid There is no single standard or framework so it falls under the distributed generation umbrella [2]. It gains from the lower line and transformer losses, as well as lower environmental impact.

However, as a result of this, the magnitude of short-term power variations would be greater, putting more strain on battery storage and potentially increasing battery scaling. Furthermore, the lifespan of the battery is harmed [3]. As a result, the issue of battery lifespan depletion and improved sizing can be solved by integrating battery and supercapacitor as a combined energy storage system but this includes a static system for improvement.

${ }^{1}$ L. Hubert Tony Raj, Assistant Professor, Department of EEE, SRM TRP Engineering College; Trichy, India, E-mail: ltonyraj@gmail.com. 
Furthermore, since PV, wind, and storage units typically have lower voltage ratings, voltage boosting is needed. As a result, the main study areas are appropriate converter configurations and control mechanisms for the application of Hybrid Energy Storage and green power sources [4].

The most popular renewable energy sources are wind and solar energy. Small-scale off-grid (microgrid) systems are deployed in rural locations. rather than constructing a transmission line to transport electricity from power plants to consumers. A microgrid system is a compact system that mostly uses solar and wind energy [5-7]. Because of the solar and wind systems' instabilities, intermittency, and high costs, non-renewable energy is becoming more common.

To ensure a consistent and reliable power supply, sources and energy storage have been added. The method is referred to as renewable energy sources are combined with other energy sources. Renewable energy networks are hybrid (HRESs) [8]. HRESs may be classified as on-grid or off-grid based on their connection to the power grid [9]. HRESs has several benefits, including the potential to use a variety of energy sources to serve a population, increasing the penetration of renewable energy sources and reducing the use of fossil fuels, and stability [10].

This paper explains the combination of both Vertical axis wind turbine system along with the Solar PV which combines to supply a nominal Resistive Load. The configuration of the hybrid module is driven with an efficient Dc to Dc converter to supply the load [11]. Here the system is under open-loop condition. The forthcoming stages of explanation fall on the Methodology, Simulation Result discussion, and Hardware implementation.

\section{Methodology}

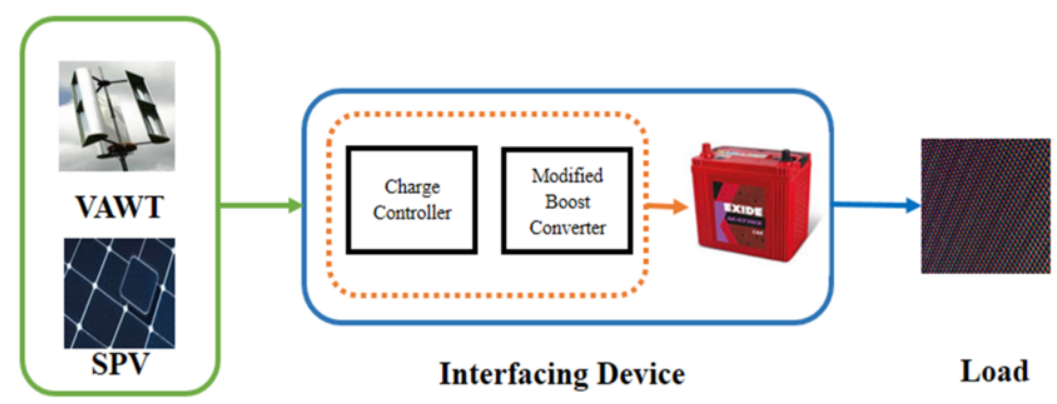

\section{Renewable Source}

Figure 1. Block Diagram of Hybrid Renewable Source with Interfacing System and Load 


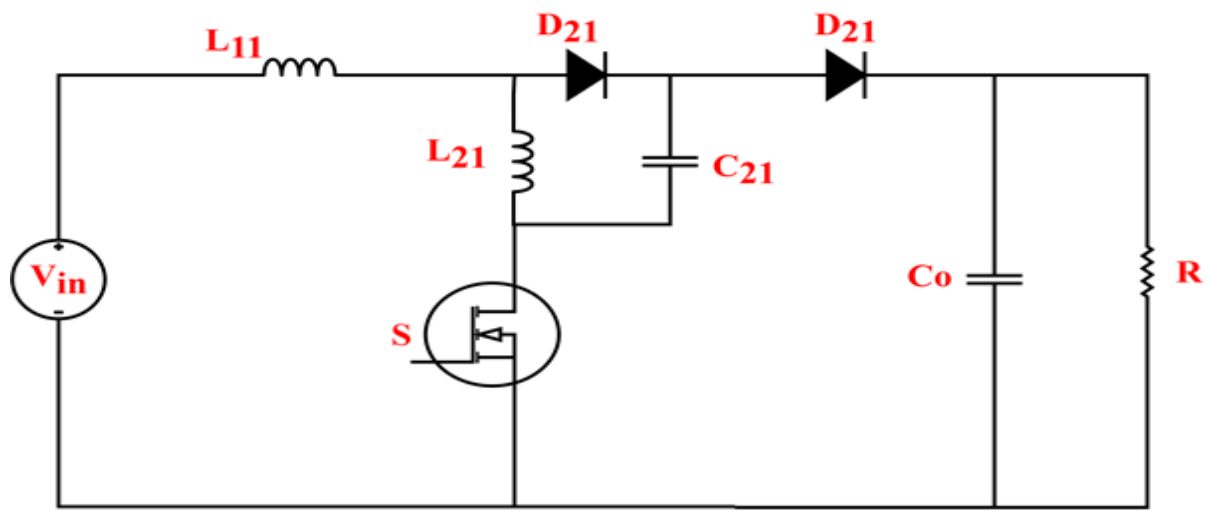

Figure 2. Circuit Diagram of the Modified Converter

The proposed modification on the converter is to interface the attained less input renewable input to a constant load Figure 1 shows the exact experimental block diagram of the proposed system.

To drive a load that is continuous in demand a constant source with some boosting technology is required. This technology needs to be in a specific rile free output regarding the effect of the ripple on the load influence the life and operation standard will be reduced in stages after some time

Figure 2, describes the circuit model of the proposed system, The operating stages of the modified circuit are as follows

During Ton D21 is forward biased and D12 is reverse biased L21 and C21 are connected in parallel, whereas $\mathrm{C} 0$ is supplied to load

During Toff D21 is reverse biased and D12 is forward biased L21 and C21 are connected in series, whereas $\mathrm{C} 0$ is supplied to load

Output Equation:

$$
\begin{gathered}
V o=\frac{2-D}{1-D} \mathrm{Vin} \\
\text { Gain }=\frac{2-D}{1-D}
\end{gathered}
$$

The Input Energy attained from the system

Stored Energy

$$
\mathrm{IEO}=\int_{\mathbf{0}}^{T 1} \boldsymbol{V}(s) \boldsymbol{i}(\mathrm{s}) \boldsymbol{d t}=\mathrm{Vs} \text { Is T }
$$

$$
\begin{aligned}
\mathrm{El} & =\frac{1}{2} \mathrm{Li} 2 \\
\mathrm{Ec} & =\frac{1}{2} \mathrm{Cv} 2
\end{aligned}
$$

\section{Results and Discussion}

The modified circuit with the combined input sources was studied using A MATLAB Simulink Tool. The design procedures under modified DC to DC converter explain the Current in the Input and the Inductor in Figure 3. The input current from the source is not exceeding $0.14 \mathrm{~A}$ maximum and the inductor current is $0.001 \mathrm{~A}$ at the stage of operation

The Gate pulse of the MOSFET switch is including $20 \mathrm{~K} \mathrm{~Hz}$ of frequency cycle for triggering the MOSFET and the voltage across the switch is shown in Figure 4. 
The Diode Voltage of Vd1 and Vd2 are perfectly inverse this is represented in the below stimulated Figure 5. Later the finite operating output stages attained from the Modified converter have the current of $2 \mathrm{~mA}$ in range together with the output voltage of $60 \mathrm{~V}$ as an average output voltage and current, this is clearly explained in Figure 6.
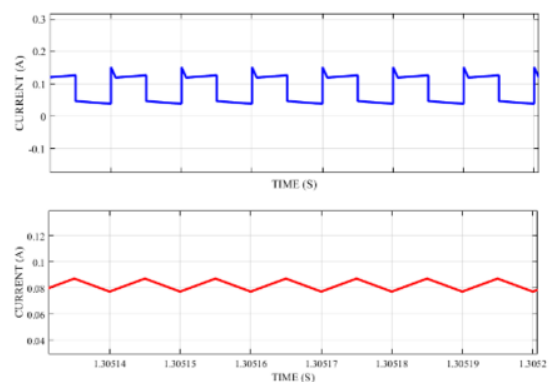

Figure 3. Input current and current at the inductor

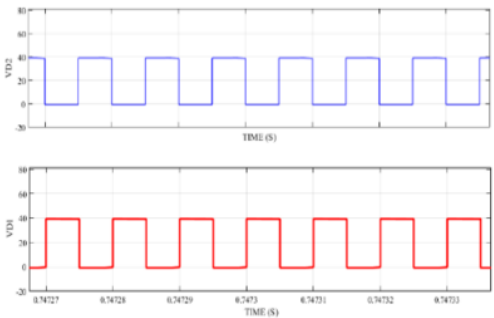

Figure 5. Diode Vd1 and Vd2 voltage
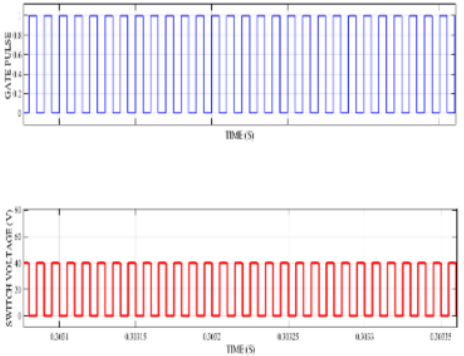

Figure 4. Gate Pulse of MOSFET and Switch Voltage
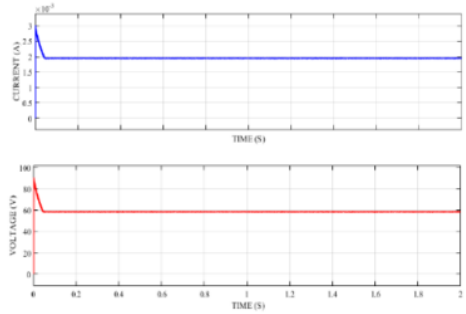

Figure 6. Output Current and Voltage

\section{Hardware results and Discussion}

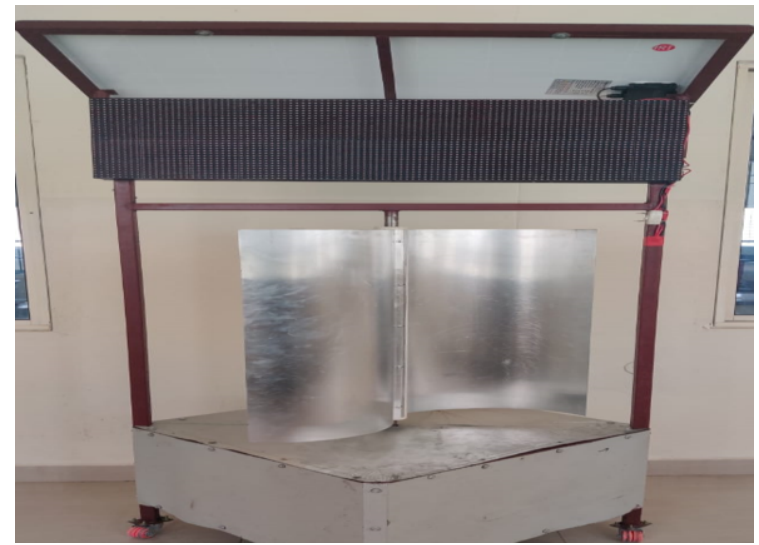

Figure 7. Experimental Setup of the proposed LED Display projecction with SPV and VAWT.

The above-represented Figure 7 is for the Hardware prototype which has a hybrid structure under open-loop conditions. The controlling input from the hybrid combination is fed to the battery using a successive charge controller and a modified 
boost converter. Table 1 represents the hardware components used for designing the overall setup of the hybrid module under common usage. This combination will be a precise design for minimum green energy extraction.

Table 1. Components and ratings for the successive design of prototype

\begin{tabular}{|l|l|l|}
\hline SI. No & \multicolumn{1}{|c|}{$\begin{array}{c}\text { List of Hardware } \\
\text { Components }\end{array}$} & \multicolumn{1}{c|}{ Rating } \\
\hline 1. & Solar Panel & 100 watts \\
\hline 2. & LED Display & Amps -5 to 6 Amps \\
\hline 3. & Aluminum Sheet & $1.25 \mathrm{~mm}$ \\
\hline 4. & Shaft & $35 \mathrm{inch}$ \\
\hline 5. & Gear & $1: 4$ ratio \\
\hline 6. & Ball Bearing & $52 \mathrm{~mm}$ Diameter \\
\hline 7. & Dynamo & 12 volts \\
\hline 8. & Charge Controller & $10-30 \mathrm{AMPS}$ \\
\hline 9. & Boost Convertor & $12-46 \mathrm{~V}$ \\
\hline 10. & Rechargeable Battery & $60 \mathrm{Ah}$ \\
\hline
\end{tabular}

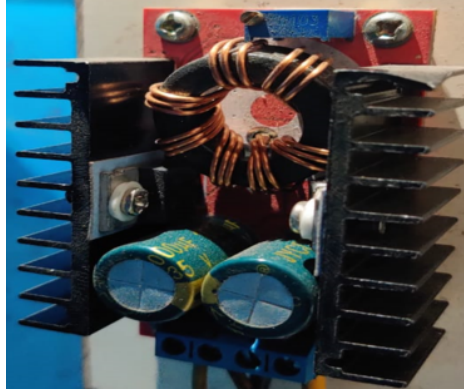

a

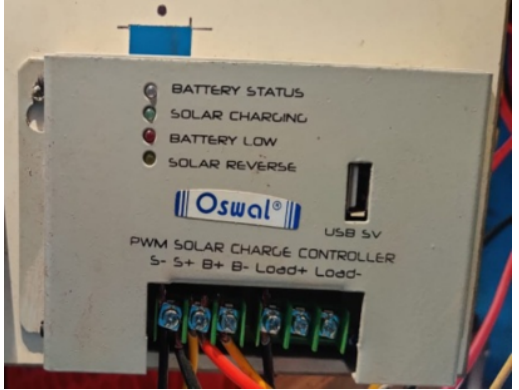

b

Figure 8. (a) Modified Converter (b) Charge Controller

The hardware is made for at VAWT that rotated under $5 \mathrm{~m} / \mathrm{s}$ of minimum wind speed design. Dynamo power output is not well sufficient to drive an LED this made an interest to support the

dynamo which provides a seasonal power supply to the club with the Solar PV system under an open-loop condition to rectify the demand. This Combination was a success to describe the efficient extraction under the conversion stages a Modified DC to DC converter is proposed. The Segmented output is boosted via this proposed converter the system is also supported with a charge controller to decide the overflow on the battery which reduces the life span of the same.

The LED display with a decorative display needs a constant supply this is achieved with the battery to let a constant power set for the LED segment. The proposed LED segment is a DOT Matrix Type of Wall that Displays the Department of EEE SRM TRPEC as shown in Figure 8.

\section{Conclusion}

The working model focus on a hybrid energy generation technique where it combines solar system and vertical axis wind turbine system, The Generated power from all the 
renewable sources needs concentration on a better state of extraction of power without any distortion. We have proposed a Modified DC to DC converter topology for providing a ripple-free output. Future work on this extension may include detailed analysis of the selection of renewable power on season and availability along with a suitable controller.

\section{References}

[1] Ravada, B. R., Tummuru, N. R., \& Ande, B. N. L. (2021). Photovoltaic-wind and hybrid energy storage integrated multi-source converter configuration for DC microgrid applications. IEEE Transactions on Sustainable Energy, 12(1), 83-91. https://doi.org/10.1109/TSTE.2020.2983985

[2] Kushwaha, R., \& Singh, B. (2021). Bridgeless Isolated Zeta-Luo Converter-Based EV Charger with PF Preregulation. IEEE Transactions on Industry Applications, 57(1), 628-636. https://doi.org/10.1109/TIA.2020.3036019

[3] Elangovan, P., \& Mohanty, N. K. (2016). PI controlled active front end super-lift converter with ripple free DC link for three phase induction motor drives. Journal of Power Electronics, 16(1), 190-204. https://doi.org/10.6113/JPE.2016.16.1.190

[4] Kushwaha, R., \& Singh, B. (2020). Design and Development of Modified BL Luo Converter for PQ Improvement in EV Charger. In IEEE Transactions on Industry Applications (Vol. 56, pp. 3976-3984). Institute of Electrical and Electronics Engineers Inc. https://doi.org/10.1109/TIA.2020.2988197

[5] Lu, Z., Li, C., Zhu, A., Luo, H., Li, C., Li, W., \& He, X. (2021). Medium Voltage Soft-Switching DC/DC Converter with Series-Connected SiC MOSFETs. IEEE Transactions on Power Electronics, 36(2), 1451-1462. https://doi.org/10.1109/TPEL.2020.3007225

[6] Sindhuja, S., \& Sripriya, S. (2013). Continuous Conduction Mode of Bridgeless SEPIC Power Factor Correction rectifier. In Proceedings of International Conference on Computation of Power, Energy, Information and Communication, ICCPEIC 2013 (pp. 28-30). IEEE Computer Society. https://doi.org/10.1109/ICCPEIC.2013.6778516

[7] Kushwaha, R., \& Singh, B. (2019). A Modified Luo Converter-Based Electric Vehicle Battery Charger with Power Quality Improvement. IEEE Transactions on Transportation Electrification, 5(4), 10871096. https://doi.org/10.1109/TTE.2019.2952089

[8] Kaliamoorthy, M., Rajasekaran, V., Raj, I. G. C., \& Raj, L. H. T. (2014). Generalised hybrid switching topology for a single-phase modular multilevel inverter. IET Power Electronics, 7(10), 2472-2485. https://doi.org/10.1049/iet-pel.2013.0847

[9] Fang Lin luo Senior Member IEEE, Hong ye Member IEEE, Muhammad H. Rashid Fellow IEEE "Super-Lift Luo-Converters"' University of West Florida Pensacola, Florida 325 14, USA.Downloaded on March 02,2021 at 06:12:58 UTC from IEEE Xplore.

[10] Mylsamy, K., Vairamani, R., Irudayaraj, G. C. R., \& Lawrence, H. T. R. (2014). Experimental validation of a cascaded single phase $\mathrm{H}$-bridge inverter with a simplified switching algorithm. Journal of Power Electronics, 14(3), 507-518. https://doi.org/10.6113/JPE.2014.14.3.507

[11] Ganesh Babu R., Karunakaran A., Manikandan G., Kalimuthu Kumar S., Selvameena R. (2021) IoT in Smart Automation and Robotics with Streaming Analytical Challenges. In: Singh K.K., Nayyar A., Tanwar S., Abouhawwash M. (eds) Emergence of Cyber Physical System and IoT in Smart Automation and Robotics. Advances in Science, Technology \& Innovation (IEREK Interdisciplinary Series for Sustainable Development). Springer, Cham. https://doi.org/10.1007/978-3-030-66222-6_7 